CLINICAL STUDY

\title{
Successful treatment of congenital hyperinsulinism with long-acting release octreotide
}

\author{
Kim-Hanh Le Quan Sang ${ }^{1,2, *}$, Jean-Baptiste Arnoux ${ }^{1, *}$, Asmaa Mamoune ${ }^{2,3}$, Cécile Saint-Martin ${ }^{4}$, \\ Christine Bellanné-Chantelot ${ }^{4}$, Vassili Valayannopoulos ${ }^{1}$, Anais Brassier ${ }^{1}$, Honorine Kayirangwa ${ }^{2,3}$, \\ Valérie Barbier $^{1}$, Christine Broissand ${ }^{5}$, Jean-Roch Fabreguettes ${ }^{5}$, Brigitte Charron ${ }^{6}$, Jean-Christophe Thalabard ${ }^{7}$ \\ and Pascale de Lonlay ${ }^{1}$ \\ ${ }^{1}$ Centre de Référence des Maladies Héréditaires du Métabolisme, Hôpital Necker-Enfants Malades, AP-HP, Université Paris Descartes, 149 Rue de Sèvres, \\ 75015 Paris, France, ${ }^{2}$ Pharmacologie Clinique, Département de Génétique, Hôpital Necker-Enfants Malades, AP-HP, Université Paris Descartes, Paris, \\ France, ${ }^{3}$ Unité de Recherche Clinique, Hôpital Ambroise Paré (AP-HP), Paris, France, ${ }^{4}$ Laboratoire de Génétique, Hôpital Pitié-Salpêtrière, AP-HP, \\ Université Pierre et Marie Curie, Paris, France, ${ }^{5}$ Service de Pharmacie, Hôpital Necker-Enfants Malades and AGEPS, AP-HP, Paris, France, ${ }^{6}$ Departement \\ d'Anesthésie, Hôpital Necker-Enfants Malades, AP-HP, Paris, France and ${ }^{7}$ MAP5 UMR, CNRS 8145, Université Paris Descartes and Hôtel-Dieu, AP-HP, \\ Paris, France \\ (Correspondence should be addressed to J-B Arnoux; Email: jean-baptiste.arnoux@nck.aphp.fr)
}

*(K-H Le Quan Sang and J-B Arnoux contributed equally to this work)

\begin{abstract}
Context: Congenital hyperinsulinism (HI) is a common cause of hypoglycemia in infancy. The medical treatment of diazoxide-unresponsive $\mathrm{HI}$ is based on a somatostatin analogue.

Objective: This study aims at replacing three daily s.c. octreotide (Sandostatin, Novartis) injections by a single and monthly i.m. injection of long-acting release (LAR) octreotide (Sandostatin LP, Novartis) in HI patients.

Subjects and method: LAR octreotide was injected every 4 weeks during 6 months and s.c. octreotide injections were stopped after the third injection of LAR octreotide. After this 6-month study, LAR octreotide was continued, with an average follow-up of 17 months. Ten HI pediatric patients unresponsive to diazoxide and currently treated with s.c. octreotide were included in the trial. Glycemias and other parameters (HbA1c, IGF1, height, weight, quality of life (QoL), and satisfaction) were monitored at each monthly visit.

Results: For all ten patients, glycemias were maintained in the usual range, HbAlc (mean 5.5\%; 95\% CI: 4.6-6.2) and IGF1 (mean $89.7 \mathrm{ng} / \mathrm{ml}$; 95\% CI: 26-153) were unchanged. Patients gained height significantly (mean $2.7 \mathrm{~cm}$; 95\% CI: 1.9-3.4) and no side effect was noted during the study and the later follow-up. Plasma octreotide levels were stable under LAR octreotide. Parents' questionnaires of general satisfaction were highly positive whereas children's QoL evaluation remained unchanged. Conclusion: In these diazoxide-unresponsive HI patients, LAR octreotide was efficient, well tolerated and contributed to a clear simplification of the medical care.
\end{abstract}

European Journal of Endocrinology 166 333-339

\section{Introduction}

Congenital hyperinsulinism (HI; MIM \#256450) is characterized by an inappropriate secretion of insulin from pancreatic $\beta$-cells. It is the most frequent cause of persistent hypoglycemia in early infancy with an estimated incidence of $1 / 50000$ births in most populations, but even higher in populations with high rates of inbreeding. Hyperinsulinemic hypoglycemia causes specific brain damage (1) and has a poor neurological outcome in the absence of adequate treatment (2).

The diagnosis of $\mathrm{HI}$ is based on recurrent non-ketotic hypoglycemia (glycemia $<3 \mathrm{mmol} / \mathrm{l}$ ) associated with concomitant inappropriate plasma insulin concentration. When $\mathrm{HI}$ is diagnosed, a specific treatment with oral diazoxide is tried for 5 days $(3,4)$. Diazoxide acts as an agonist of a $\mathrm{K}_{\text {ATP }}$ channel harbored on the $\beta$-cell plasma membrane. However, in neonates, most severe HIs are caused by mutations in the genes encoding the subunits of this $\mathrm{K}_{\mathrm{ATP}}$ channel (ABCC8 and KCNJ11 genes) (5), which bestow a diazoxideunresponsive profile to most patients (6). In case of diffuse HI, where all $\beta$-cells are involved throughout the pancreas, long-term and intensive medical treatment is the only alternative to the near-total pancreatectomy, which leads to recurrent post-operative hypoglycemias in $60 \%$ of patients and then insulin-dependent diabetes 
within a few years in all patients $(7,8)$. Thus, the challenge for diazoxide-unresponsive diffuse $\mathrm{HI}$ is to find an efficient and well-tolerated long-term medical treatment, especially as progressive $\beta$-cells apoptosis may be responsible for spontaneous remission (9-12).

Octreotide, when effective, is considered the only alternative with diet to a near-total pancreatectomy (13), but it must be administered s.c. three to four times a day, or continuously with a s.c. pump $(3,14$, 15).

An efficacy tolerance trial with the long-acting release (LAR) octreotide (Sandostatin LP, Novartis) was performed in ten diazoxide-unresponsive HI patients, currently treated with s.c. octreotide.

\section{Research design and methods}

This clinical trial was promoted by Assistance PubliqueHôpitaux de Paris (AP-HP), approved by the Institutional Ethics Committee (CPP-Ile de France 2) and registered at the National Health Authority (AFSSAPS) and at the International Protocol Registration System (ClinicalTrials.gov, NCT00987168). In accordance with the Declaration of Helsinki, written informed consent was obtained from parents and patients.

Ten diazoxide-unresponsive HI patients (four boys, six girls), with glycemia constantly $>3 \mathrm{mmol} / \mathrm{l}$ during the inclusion visit and treated with s.c. octreotide (three daily s.c. injections or continuous administration using a s.c. pump) were included in this trial. The average age at inclusion was 4.7 years old (from 1.3 to 8.5 years). Patients with gallbladder stones were excluded from the study as well as patients unresponsive to s.c. octreotide. The patients' description (age, genetics, and treatment) is summarized in Table 1.

The genetic analysis, performed in probands on genomic DNA extract from peripheral lymphocytes, included: i) sequencing of the coding sequence and exon/intron boundaries of KCNJ11, ABCC8, and GCK genes and of the $A B C C 8$ promoter region; and ii) a multiplex ligation-dependant probe assay to screen for $A B C C 8$ genomic rearrangement (5). Three patients had one mutation in the ABCC 8 gene (two inherited from their father and one de novo mutation) and exhibited a diffuse pattern at positron emmission tomography (PET) scan, suggesting the recently described dominant ABCC8 diazoxide-unresponsive HI (16). Two patients harbored two ABCC8 mutations; in five patients, no mutation nor deletion was found in $A B C C 8, K C N J 1$, and GCK genes, and one patient had Kabuki syndrome (see Table 1). These results illustrate the genetic heterogeneity of diazoxide-unresponsive HI. During the 3 months prior to inclusion in this trial, s.c. octreotide had to be titrated up in nine patients because of moderate recurrent hypoglycemia during routine follow-up evaluations. Glycemia normalized with higher doses of s.c. octreotide, showing that this treatment was both efficient and necessary in these patients. In all ten patients, after titration, the current dose of s.c. octreotide ranged from 32 to $60 \mu \mathrm{g} / \mathrm{kg}$ per day (3) and no hypoglycemia was notified within the $48 \mathrm{~h}$ assessment of the inclusion visit.

The patients participated in this trial for 6 months and then LAR octreotide was continued with an actual follow-up of a maximum of 2 years. Patients were hospitalized every 4 weeks for $48-72 \mathrm{~h}$ in the Metabolism Unit of Necker-Enfants Malades Hospital for a total of seven visits on site (V1 to V7). I.m. injection of LAR octreotide (Sandostatin LP, Novartis) was administered on the second day of each hospitalization. The i.m. dose injected to each patient was equal to the cumulative dose over 31 days of their usual s.c. octreotide (Sandostatin, Novartis).

The substitution from s.c. to LAR octreotide was performed as follows: at visit 1 (V1), during the first

Table 1 Clinical characteristics and genetics of our ten patients. The sequencing of the coding sequence and exon/intron boundaries of $K C N J 11, A B C C 8$, and $G C K$ genes and the $A B C C 8$ promoter region was performed in probands on genomic DNA extract from peripheral lymphocytes, as well as a search for $A B C C 8$ genomic rearrangement by multiplex ligation-dependant probe assay.

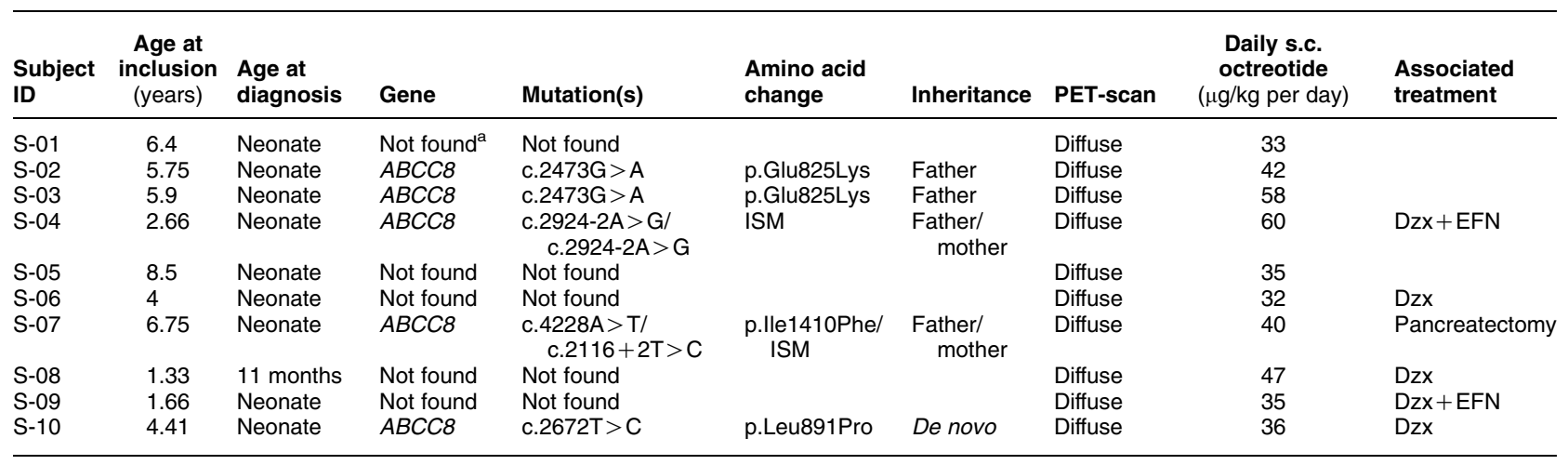

Dzx, diazoxide; EFN, enteral feeding overnight; ISM, intronic splice mutation.

apatient S-01 has Kabuki syndrome. 
$24 \mathrm{~h}$, patients were under their usual treatment with s.c. octreotide. After $24 \mathrm{~h}$, the patients received the first i.m. injection of LAR octreotide and they continued s.c. octreotide. At visit 2 (V2), the patients were under treatment with s.c. octreotide and received the second i.m. injection of LAR octreotide. During visit 3 (V3), injections of s.c. octreotide were stopped the day of the third i.m. injection of LAR octreotide. Finally, at visit 4 (therefore during V4, V5, V6, and V7), the patients received only the monthly i.m. injection of LAR octreotide.

Pain induced by i.m. injection was prevented by the use of xylocaine cream at the injection point and the intra-rectal administration of nalbuphine $(0.3 \mathrm{mg} / \mathrm{kg})$ and midazolam $(0.1 \mathrm{mg} / \mathrm{kg})$. After each i.m. injection, vital signs and clinical observations were monitored every $30 \mathrm{~min}$ for $2 \mathrm{~h}$ (Supplementary Table 1, see section on supplementary data given at the end of this article). Pain induced by the injections of octreotide was evaluated during the trial by questionnaires, during V1 to evaluate the s.c. injections, and during V7 to evaluate the i.m. injection.

During each visit, the following were measured: i) glycemia before and after four meals, at midnight, and at $0400 \mathrm{~h}$; ii) HbAlc; iii) ALAT/ASAT, $\beta$-glutamyl transpeptidase, and alkaline phosphatase; and iv) blood count. As octreotide may inhibit GH, height and insulin-like growth factor 1 (IGF1) were monitored at each visit. Patients were screened for gallbladder stones by abdominal ultrasonography during V1 and the V7.

\section{Octreotide profile analysis}

Plasma octreotide levels before each i.m. injection of LAR octreotide were determined by RIA based on the competition between ${ }^{125}$ I-octreotide and octreotide for a fixed number of antibody-binding sites. Standards, quality controls, and samples were incubated using

${ }^{125}$ I-octreotide tracer and anti-serum. After a charcoal separation, the bound radioactivity was determined in a gamma counter. The limit of quantification for this assay was $50 \mathrm{pg} / \mathrm{ml}$ (Atlanbio, unpublished data). Blood was sampled just before an i.m. injection, so under a treatment with s.c. octreotide alone at V1, then under a treatment with both s.c. and LAR octreotide at V2 and $\mathrm{V} 3$, and finally under LAR octreotide alone for visits $\mathrm{V} 4$ to $\mathrm{V} 7$.

\section{Quality of life}

During V1 and V7, quality of life (QoL, physical and psychological domains) was evaluated using a QoL questionnaire. Children from 3 to 11 years old completed an AUQUEI picture questionnaire under the supervision of a psychologist (17). Parents also reported their children's QoL using the QUALIN questionnaires at V1 and V7 (18), as well as a questionnaire of their general satisfaction at the end of the trial (V7).

\section{Statistical analysis}

The continuously distributed variables were analyzed using a linear random-mixed model for repeated measurements, assuming a Gaussian error and an identity link function. Analyses were carried out either by considering each visit at a different time or by grouping the visits according to the treatment exposure: s.c., s.c. + LAR, or LAR. Either the times of the visits or the treatment exposure was considered as a fixed factor, whereas the individual intercept was considered as random. In each analysis, V1 or the s.c. treatment was considered as the reference (intercept).

Hypoglycemic episodes were categorized according to different glycemic levels: $<3.0,<2.5$, and $<2.0 \mathrm{mmol} / \mathrm{l}$. Two methods were used to compare their occurrences between the different treatment period exposures: i) the first method used a naïve nonparametric Fisher comparison test of the total number of detected episodes in relation to the total number of glycemic determinations within the corresponding period; and ii) the second method used a generalized linear random-mixed model assuming a binomial family with a logic link function, in order to take into account a possible individual's random effect, inducing a correlation between their blood concentrations.

The standard error, $P$ value, and 95\% confidence intervals for the basal mean level estimate at V1 and the respective differential effects at the following visits were calculated.

The items of the QoL questionnaires were analyzed separately as ordinal categorical variables, with repeated measurements at V1 and V7, using the nonparametric Friedman test. The blocking variable was the subject. Bonferroni correction for multiple testing was subsequently applied.

All the analyses were carried out with R (19), using packages lattice for graphics (Sarkar D (2010): Lattice; Lattice Graphics, R package version 0.18-8), MASS for continuous variables (function glmm PQL) (20), and coin for categorical variables (function Friedman test) (21).

\section{Results}

The occurrence of hypoglycemia during the 6-month treatment period with LAR octreotide is summarized in Table 2. For all ten patients, blood glucose levels, determined before and after four meals, at midnight, and at $0400 \mathrm{~h}$, for 48-72 h at every monthly visit, were maintained in the usual range, both before and after the interruption of s.c. octreotide during the study. Seven of the ten patients presented at least one hypoglycemia $<3 \mathrm{mmol} / \mathrm{l}$. However, hypoglycemia was rare and isolated (29/1182 glycemias), 26/29 hypoglycemias were minor (between 2.5 and $3 \mathrm{mmol} / \mathrm{l}$ ), and only one severe at $1.9 \mathrm{mmol} / \mathrm{l}$ while the patient was 
Table 2 Number of glycemias and hypoglycemias according to different thresholds ( 2 or 2.5 or $3 \mathrm{mmol} / \mathrm{l})$ at each visit (from V1 to V7) for each patient (from S-01 to S-11). In each cell, from top to bottom: All, total number of glycemic determinations; <3.0, number of glycemia below $3.0 \mathrm{mmol} / \mathrm{l}$; $<2.5$, number of glycemia below $2.5 \mathrm{mmol} / \mathrm{l} ;<2.0$, number of glycemia below $2.0 \mathrm{mmol} / \mathrm{l}$.

\begin{tabular}{|c|c|c|c|c|c|}
\hline Subject & Threshold & s.c. & s.c. + LAR & LAR & Total \\
\hline \multirow[t]{4}{*}{ S-01 } & All & 7 & 35 & 86 & 128 \\
\hline & $<3.0 \mathrm{mmol} / \mathrm{l}$ & 0 & 0 & 0 & 0 \\
\hline & $<2.5 \mathrm{mmol} / \mathrm{l}$ & 0 & 0 & 0 & 0 \\
\hline & $<2.0 \mathrm{mmol} / \mathrm{l}$ & 0 & 0 & 0 & 0 \\
\hline \multirow[t]{4}{*}{ S-02 } & All & 5 & 28 & 89 & 122 \\
\hline & $<3.0 \mathrm{mmol} / \mathrm{l}$ & 0 & 0 & 1 & 1 \\
\hline & $<2.5 \mathrm{mmol} / \mathrm{l}$ & 0 & 0 & 0 & 0 \\
\hline & $<2.0 \mathrm{mmol} / \mathrm{l}$ & 0 & 0 & 0 & 0 \\
\hline \multirow[t]{4}{*}{ S-03 } & All & 6 & 35 & 87 & 128 \\
\hline & $<3.0 \mathrm{mmol} / \mathrm{l}$ & 0 & 0 & 1 & 1 \\
\hline & $<2.5 \mathrm{mmol} / \mathrm{l}$ & 0 & 0 & 0 & 0 \\
\hline & $<2.0 \mathrm{mmol} / \mathrm{l}$ & 0 & 0 & 0 & 0 \\
\hline \multirow[t]{4}{*}{ S-04 } & All & 6 & 38 & 84 & 128 \\
\hline & $<3.0 \mathrm{mmol} / \mathrm{l}$ & 0 & 0 & 8 & 8 \\
\hline & $<2.5 \mathrm{mmol} / \mathrm{l}$ & 0 & 0 & 0 & 0 \\
\hline & $<2.0 \mathrm{mmol} / \mathrm{l}$ & 0 & 0 & 0 & 0 \\
\hline \multirow[t]{4}{*}{ S-05 } & All & 4 & 25 & 70 & 99 \\
\hline & $<3.0 \mathrm{mmol} / \mathrm{l}$ & 0 & 0 & 0 & 0 \\
\hline & $<2.5 \mathrm{mmol} / \mathrm{l}$ & 0 & 0 & 0 & 0 \\
\hline & $<2.0 \mathrm{mmol} / \mathrm{l}$ & 0 & 0 & 0 & 0 \\
\hline \multirow[t]{4}{*}{ S-06 } & All & 8 & 31 & 77 & 116 \\
\hline & $<3.0 \mathrm{mmol} / \mathrm{l}$ & 0 & 0 & 0 & 0 \\
\hline & $<2.5 \mathrm{mmol} / \mathrm{l}$ & 0 & 0 & 0 & 0 \\
\hline & $<2.0 \mathrm{mmol} / \mathrm{l}$ & 0 & 0 & 0 & 0 \\
\hline \multirow[t]{4}{*}{ S-07 } & All & 4 & 31 & 82 & 117 \\
\hline & $<3.0 \mathrm{mmol} / \mathrm{l}$ & 0 & 1 & 4 & 5 \\
\hline & $<2.5 \mathrm{mmol} / \mathrm{l}$ & 0 & 1 & 1 & 2 \\
\hline & $<2.0 \mathrm{mmol} / \mathrm{l}$ & 0 & 0 & 1 & 1 \\
\hline \multirow[t]{4}{*}{ S-09 } & All & 4 & 27 & 81 & 112 \\
\hline & $<3.0 \mathrm{mmol} / \mathrm{l}$ & 0 & 1 & 2 & 3 \\
\hline & $<2.5 \mathrm{mmol} / \mathrm{l}$ & 0 & 0 & 0 & 0 \\
\hline & $<2.0 \mathrm{mmol} / \mathrm{l}$ & 0 & 0 & 0 & 0 \\
\hline \multirow[t]{4}{*}{ S-10 } & All & 6 & 31 & 74 & 111 \\
\hline & $<3.0 \mathrm{mmol} / \mathrm{l}$ & 0 & 5 & 0 & 5 \\
\hline & $<2.5 \mathrm{mmol} / \mathrm{l}$ & 0 & 1 & 0 & 1 \\
\hline & $<2.0 \mathrm{mmol} / \mathrm{l}$ & 0 & 0 & 0 & 0 \\
\hline \multirow[t]{4}{*}{ S-11 } & All & 6 & 33 & 82 & 121 \\
\hline & $<3.0 \mathrm{mmol} / \mathrm{l}$ & 0 & 2 & 4 & 6 \\
\hline & $<2.5 \mathrm{mmol} / \mathrm{l}$ & 0 & 0 & 0 & 0 \\
\hline & $<2.0 \mathrm{mmol} / \mathrm{l}$ & 0 & 0 & 0 & 0 \\
\hline \multirow[t]{4}{*}{ Total } & Total & 56 & 314 & 812 & 1182 \\
\hline & $<3.0 \mathrm{mmol} / \mathrm{l}$ & 0 & 9 & 20 & 29 \\
\hline & $<2.5 \mathrm{mmol} / \mathrm{l}$ & 0 & 2 & 1 & 3 \\
\hline & $<2.0 \mathrm{mmol} / \mathrm{l}$ & 0 & 0 & 1 & 1 \\
\hline
\end{tabular}

perfectly asymptomatic (Table 2). Individual $\mathrm{HbAlc}$ levels were within the normal range during all the study visits (Fig. 1) and stable whatever the treatment was (s.c. octreotide alone, s.c. + LAR, or LAR alone).

The mean weight and height of the patients showed a significant and normal increase between V1 and V7, and patients continued to grow steadily in height and weight along their growth curves. IGF1 was statistically unchanged throughout the study (Supplementary Table 1). Other clinical and biological parameters were also in the normal range during the trial and remained stable. Further analysis also indicated that these parameters were not significantly modified according to the treatment change, with s.c., s.c. + LAR, or LAR octreotide (Supplementary Table 2, see section on supplementary data given at the end of this article). No gallbladder stones were detected in the abdominal ultrasonographies performed at V1 and V7.

Plasma octreotide levels were determined before each LAR octreotide injection (Fig. 2). During V1 we observed huge variations in octreotidaemia, ranging from 2.4 to $25.8 \mathrm{ng} / \mathrm{ml}(12.6 \pm 10.7$; mean $\pm D S)$, because blood was sampled at a random time from the s.c. injection. At V4, octreotidaemia under treatment with LAR octreotide alone was stable with a mean octreotidemia of $4.5 \pm 1.3 \mathrm{ng} / \mathrm{ml}$.

The i.m. injection was well tolerated (Supplementary Table 1). Hematomas at the i.m. injection point were 


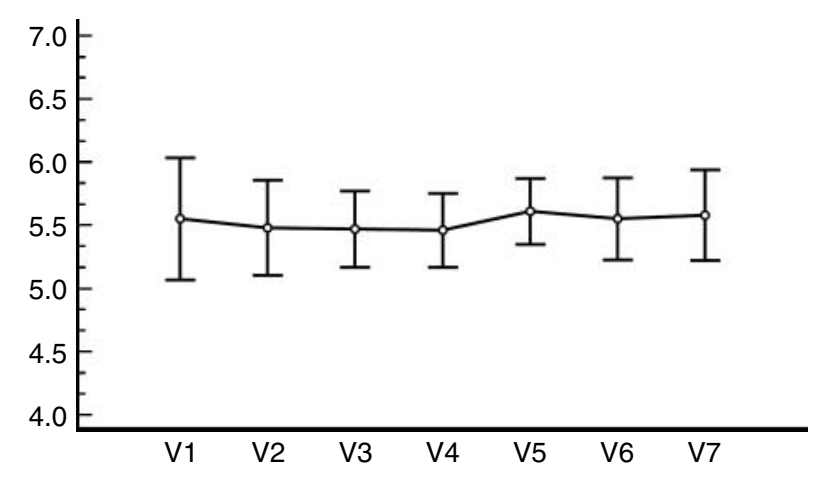

Figure $1 \mathrm{HbA} 1 \mathrm{c}$ levels in the ten patients (mean \pm s.D.) during the seven monthly visits of the study. HbA1c, which is expressed as \%, were determined during each monthly visit, initially under a treatment with s.c. octreotide alone (V1), under both s.c. and monthly LAR octreotide (V2 and V3), and then under monthly LAR octreotide alone (V4-V7).

notified three times out of 70 i.m. injections performed in the study. On the pain questionnaire, most parents reported their child's fear before the i.m. injection. Most of the patients ( $7 / 10$ patients) cried during and after the i.m. injections. The patients' fear and reactions to pain seemed more intense than after s.c. injections; however, this did not reach statistical difference.

The QoL evaluations of the children were not able to detect any change after the switch of the treatment. The AUQUEI children's questionnaire found a score of $8.0 \pm 1.33$ at V7 vs $7.9 \pm 1.45$ at V1 ('10', best QoL; ' 1 ', worse QoL; \pm DS; Supplementary Table 3, see section on supplementary data given at the end of this article). However, the parents' satisfaction questionnaire assessed at the end of the trial (V7) qualified this new treatment as 'excellent' in $100 \%$ of parents, because it significantly improved their QoL.

No side effects occurred during an average follow-up of 17 months.

\section{Discussion}

Somatostatin (SST) is secreted by $\delta$-cells in the pancreatic islets and by extra-islet neuroendocrine cells. SST inhibits both insulin and glucagon secretions. Octreotide is an octapeptide SST analogue, which has a high affinity for the SST receptors $\operatorname{sstr}_{2}$ and $\operatorname{sstr}_{5}$. The subsequent downstream mechanisms leading to a decrease in the insulin secretion are numerous: activation of potassium channels at the $\beta$-cell membrane, inhibition of the intracellular mobilization of calcium, decrease in the insulin gene promoter activity, etc.

Because of its short half-life (100 min), octreotide is usually administered s.c. every $6-8 \mathrm{~h}$. However, octreotide can also be administered continuously using a s.c. pump because some hypoglycemia can occur several hours after the s.c. injection, when the plasma level of octreotide drops under the efficacy threshold.

Two long-acting SST analogues were developed for the treatment of neuroendocrine tumors in adults: the LAR octreotide (22) and the lanreotide autogel. Both molecules are octapeptides but differ by their pharmacokinetic profiles. LAR octreotide is formulated as microspheres of biodegradable polymer containing the active peptides. After a single i.m. injection, the plasma octreotide concentrations remain very low during the first 2 weeks after the injection and then increase quickly to reach a plateau, which remains stable between days 14 and 42 (23). This pharmacokinetic profile ensures a continuously stable plasma concentration of octreotide over at least 4 weeks.

Patients from this study were treated with higher doses of s.c. octreotide (ranging from 32 to $60 \mu \mathrm{g} / \mathrm{kg}$ per day) than other medical teams recommend (5-15 $\mu \mathrm{g} / \mathrm{kg}$ per day) (24). However, when HI children were shifted to LAR octreotide, the mean octreotidaemia (4.5 $\pm 1.3 \mathrm{ng} / \mathrm{ml}$ ) was within the range of octreotidaemia measured in adults treated monthly with LAR octreotide $30 \mathrm{mg}(25)$.

The results of this study showed that in our ten patients, a monthly i.m. injection of LAR octreotide (Sandostatin LP, Novartis) was efficient in maintaining glycemia unchanged, without altering the normal weight-and-growth development of the children, but with a clear simplification of their medical care and the QoL of their families. Some isolated hypoglycemias were notified during the trial, but only three were below $2.5 \mathrm{mmol} / \mathrm{l}$ (three hypoglycemias over 1182 glycemias sampled). Our results may not apply to all diazoxideunresponsive HI. Indeed, our patients' average age was 4.7 years old; thus, the severity of their $\mathrm{HI}$ already improved compared with their neonatal period. Moreover, we do not recommend the use of LAR octreotide during the neonatal period because the dose of octreotide

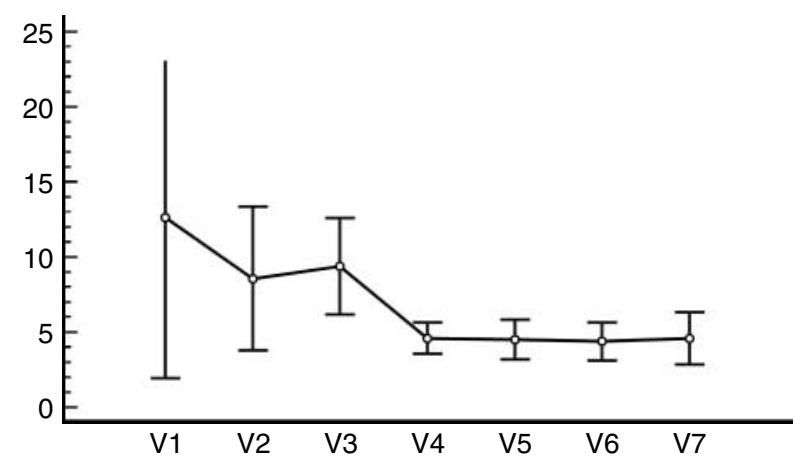

Figure 2 Evolution of plasma octreotide levels in our ten patients (mean \pm s.D.) during the trial. Plasma octreotide plasma levels, expressed as $\mathrm{ng} / \mathrm{ml}$, were determined at every monthly visit, initially under a treatment with s.c. octreotide alone (V1), under both s.c. and monthly LAR octreotide (V2 and V3), and then under monthly LAR octreotide alone (V4-V7). 
must be carefully titrated in neonates, several times a week, especially since a risk of nectrotizing enterocolitis may require the octreotide to be stopped abruptly (26).

During the first three visits (V1, V2, V3), patients cumulated the dose of s.c. and LAR octreotide, as 2 months are necessary for LAR octreotide to reach its plateau. This may have exposed the patients to an over dosage of octreotide during these 2 months. However, the clinical and biological parameters according to the treatment change were not significantly modified. Although octreotide is also the treatment of acromegaly in adults and overgrowth in children, there is no published report so far about slowing of growth velocity in HI patients under octreotide treatment. The 6-month period of this study is certainly insufficient to screen for growth velocity slowing; however, octreotide is used in HI for 20 years and no major long-term side effect was reported. Moreover, lanreotide acetate, another longacting SST analogue, was administered in two patients with a follow-up of 3 and 5 years, with no apparent side effects (27), as well as in a third patient but the length of the follow-up was not precise (28). Finally, no growth failure was observed in our patients after this study, nor after 12-25 months of treatment. SST analogues were also suspected to delay puberty in treated rhesus monkeys (29), but this was not reported in humans. The long-term follow-up of more patients must also include pubertal evaluation.

During our study, no severe side effects were reported. Hematoma at the site of injection was noted on three occasions (3/70 i.m.). None of the patients shifted to LAR octreotide presented abdominal pain, nausea, diarrhea, or steatorrhea. None developed gallbladder stones. Fear and pain seem more intense during i.m. injection compared with s.c. injection; however, it does not meet statistical significance and one single monthly i.m. injection replaced 84 s.c. injections over 28 days. A long-term careful follow-up is necessary to assess longterm effects of LAR octreotide, especially on growth and puberty.

Surprisingly, not the children but their parents reported a clear improvement of their QoL. It may be due to the lack of specificity of the children's questionnaires and the small number of patients enrolled in the study. All parents declared many improvements in their daily life (no need to organize a daily injection at school, possibility to go for a journey without ice-packs to conserve s.c. octreotide etc.). All families were requested to continue with LAR octreotide after the end of this trial and are currently continuing the LAR monthly injection in their local hospitals. The painkiller treatment was subsequently lightened to xylocaine cream alone or with a systemic treatment (e.g. paracetamol and inhaled nitric oxide) in specific cases. We may have overestimated the pain induced by this large i.m. injection when we designed the study.

In conclusion, LAR octreotide contributes to an undeniable simplification of the medical care of diazoxide-unresponsive diffuse HI, as one monthly i.m. injection can replace three daily s.c. injections of octreotide. Moreover, the particular pharmacokinetic profile of LAR octreotide, with a plateau spanning at least 4 weeks, will give the possibility to decrease the dose administered or to space the injections to every 5 or 6 weeks.

\section{Supplementary data}

This is linked to the online version of the paper at http://dx.doi.org/10. 1530/EJE-11-0874.

\section{Declaration of interest}

The authors declare that there is no conflict of interest that could be perceived as prejudicing the impartiality of the research reported.

\section{Funding}

This study was sponsored by Assistance Publique-Hôpitaux de Paris (via Délégation de la Recherche Clinique et du Développement, Hôpital Saint-Louis, AP-HP) and was supported by a grant from the Contrat de Recherche Clinique (CRC 07024), with the collaboration of Novartis-France.

\section{Author contribution statement}

K-H Le Quan Sang designed the study, coordinated the clinical trial, and wrote the article. J-B Arnoux performed the follow-up of patients and wrote the article. V Valayannopoulos and A Brassier performed the follow-up of patients. A Mamoune and H Kayirangwa organized the logistics of the project and researched data. V Barbier performed the tests of quality of life. C Broissand and J-R Fabreguettes performed drug dispensation. B Charron monitored and advised to prevent the i.m. injection-related pain. J-C Thalabard designed the clinical trial, performed the statistical analysis, and wrote the article. P de Lonlay initiated the study, supervised the patients, and wrote the article.

\section{Acknowledgements}

The authors thank Dr Christine Bellané-Chantelot, Genetics Department, La Pitié-Salpétrière Hospital, AP-HP, for her helpful genetic investigation and the Clinical Research Unit, Ambroise Paré Hospital, AP-HP (Prof. Philippe Aergerter) for its logistical support.

\section{References}

1 Filan PM, Inder TE, Cameron FJ, Kean MJ \& Hunt RW. Neonatal hypoglycemia and occipital cerebral injury. Journal of Pediatrics 2006148 552-555. (doi:10.1016/j.jpeds.2005.11.015)

2 Menni F, de Lonlay P, Sevin C, Touati G, Peigné C, Barbier V, Nihoul-Fékété C, Saudubray JM \& Robert JJ. Neurologic outcomes of 90 neonates and infants with persistent hyperinsulinemic hypoglycemia. Pediatrics 2001107 476-479. (doi:10.1542/peds. 107.3.476)

3 Arnoux JB, de Lonlay P, Ribeiro MJ, Hussain K, Blankenstein O, Mohnike K, Valayannopoulos V, Robert JJ, Rahier J, Sempoux C, Bellanné C, Verkarre V, Aigrain Y, Jaubert F, Brunelle F \& NihoulFékété C. Congenital hyperinsulinism. Early Human Development 201086 287-294. (doi:10.1016/j.earlhumdev.2010.05.003)

4 Hussain K, Blankenstein O, De Lonlay P \& Christesen HT. Hyperinsulinaemic hypoglycaemia: biochemical basis and the 
importance of maintaining normoglycaemia during management. Archives of Disease in Childhood 200792 568-570. (doi:10.1136/ adc.2006.115543)

5 Bellanné-Chantelot C, Saint-Martin C, Ribeiro MJ, Vaury C, Verkarre V, Arnoux JB, Valayannopoulos V, Gobrecht S, Sempoux C, Rahier J, Fournet JC, Jaubert F, Aigrain Y, NihoulFékété C \& de Lonlay P. ABCC8 and KCNJ11 molecular spectrum of 109 patients with diazoxide-unresponsive congenital hyperinsulinism. Journal of Medical Genetics 201047 752-759. (doi:10. 1136/jmg.2009.075416)

6 de Lonlay P, Fournet JC, Touati G, Martin D, Sevin C, Delagne V, Sempoux C, Brusset C, Laborde C, Vassault A, Rahier J, Junien C, Brunelle F, Nihoul Fékété C, Robert JJ \& Saudubray JM. Heterogeneity of persistent hyperinsulinemic hypoglycemia of infancy. A series of 175 cases. European Journal of Pediatrics 2002 $16137-48$.

7 de Lonlay-Debeney P, Poggi-Travert F, Fournet JC, Sempoux C, Vici CD, Brunelle F, Touati G, Rahier J, Junien C, Nihoul-Fékété C, Robert JJ \& Saudubray JM. Clinical features of 52 neonates with hyperinsulinism. New England Journal of Medicine $19993 \mathbf{3 4 0}$ 1169-1175. (doi:10.1056/NEJM199904153401505)

8 Cherian MP \& Abduljabbar MA. Persistent hyperinsulinemic hypoglycemia of infancy (PHHI): long-term outcome following $95 \%$ pancreatectomy. Journal of Pediatric Endocrinology and Metabolism 200518 1441-1448. (doi:10.1515/JPEM.2005.18. 12.1441)

9 Kumaran A, Kapoor RR, Flanagan SE, Ellard S \& Hussain K. Congenital hyperinsulinism due to a compound heterozygous ABCC8 mutation with spontaneous resolution at eight weeks. Hormone Research in Pediatrics 201073 287-292. (doi:10.1159/ 000284394)

10 Glaser B \& Landau H. Long-term treatment with the somatostatin analogue SMS 201-995: alternative to pancreatectomy in persistent hyperinsulinaemic hypoglycaemia of infancy. Digestion 199045 27-35. (doi:10.1159/000200258)

11 Glaser B, Hirsch HJ \& Landau H. Persistent hyperinsulinemic hypoglycemia of infancy: long-term octreotide treatment without pancreatectomy. Journal of Pediatrics 1993123 644-650. (doi:10. 1016/S0022-3476(05)80970-9)

12 Mazor-Aronovitch K, Gillis D, Lobel D, Hirsch HJ, PinhasHamiel O, Modan-Moses D, Glaser B \& Landau H. Long-term neurodevelopmental outcome in conservatively treated congenital hyperinsulinism. European Journal of Endocrinology 2007157 491-497. (doi:10.1530/EJE-07-0445)

13 Thornton PS, Alter CA, Katz LE, Baker L \& Stanley CA. Short- and long-term use of octreotide in the treatment of congenital hyperinsulinism. Journal of Pediatrics $1993 \quad 123 \quad 637-643$. (doi:10.1016/S0022-3476(05)80969-2)

14 Aynsley-Green A, Hussain K, Hall J, Saudubray JM, NihoulFékété C, De Lonlay-Debeney P, Brunelle F, Otonkoski T, Thornton P \& Lindley KJ. Practical management of hyperinsulinism in infancy. Archives of Disease in Childhood. Fetal and Neonatal Edition 200082 98-107. (doi:10.1136/fn.82.2.F98)

15 Kapoor RR, Flanagan SE, James C, Shield J, Ellard S \& Hussain K. Hyperinsulinaemic hypoglycaemia. Archives of Disease in Childhood 200994 450-457. (doi:10.1136/adc.2008.148171)

16 Macmullen CM, Zhou Q, Snider KE, Tewson PH, Becker SA, Aziz AR, Ganguly A, Shyng SL \& Stanley CA. Diazoxide-unresponsive congenital hyperinsulinism in children with dominant mutations of the $\beta$-cell sulfonylurea receptor SUR1. Diabetes $2011 \mathbf{6 0}$ 1797-1804. (doi:10.2337/db10-1631)

17 Manificat S, Dazord A, Cochat P \& Nicolas J. Evaluation of the quality of life in pediatrics: how to collect the point of view of children. Archives de Pédiatrie 19974 1238-1246. (doi:10.1016/ S0929-693X(97)82616-4)

18 Manificat S, Dazord A, Langue J, Danjou G, Bauche P, Bovet F, Cubells J, Luchelli R, Tockert E \& Conway K. Evaluation of the quality of life of infants and very young children: validation of a questionnaire. Multicenter European Study. Archives de Pédiatrie 20007 605-614. (doi:10.1016/S0929-693X(00)80127-X)

$19 \mathrm{R}$ Development Core Team. In A Language and Environment for Statistical Computing. Vienna: R Foundation for Statistical Computing, 2010.

20 Venables WN \& Ripley BD. In Modern Applied Statistics with S. Fourth Edition. New York: Springer, 2002.

21 Hothorn T, Hornik K, van de Wie M \& Zeileis A. Implementing a class of permutation tests: the coin package. Journal of Statistical Software $2008 \mathbf{2 8} 1-23$.

22 Grass P, Marbach P, Bruns C \& Lancranjan I. Sandostatin LAR (microencapsulated octreotide acetate) in acromegaly: pharmacokinetic and pharmacodynamic relationships. Metabolism 1996 45 27-30. (doi:10.1016/S0026-0495(96)90075-X)

23 Astruc B, Marbach P, Bouterfa H, Denot C, Safari M, Vitaliti A \& Sheppard M. Long-acting octreotide and prolonged-release lanreotide formulations have different pharmacokinetic profiles. Journal of Clinical Pharmacology 200545 836-844. (doi:10. 1177/0091270005277936)

24 Palladino AA \& Stanley CA. A specialized team approach to diagnosis and medical versus surgical treatment of infants with congenital hyperinsulinism. Seminars in Pediatric Surgery 201120 32-37. (doi:10.1053/j.sempedsurg.2010.10.008)

25 Rubin J, Ajani J, Schirmer W, Venook AP, Bukowski R, Pommier R, Saltz L, Dandona P \& Anthony L. Octreotide acetate long-acting formulation versus open-label subcutaneous octreotide acetate in malignant carcinoid syndrome. Journal of Clinical Oncology 1999 17 600-606.

26 Laje P, Halaby L, Adzick NS \& Stanley CA. Necrotizing enterocolitis in neonates receiving octreotide for the management of congenital hyperinsulinism. Pediatric Diabetes 201011 142-147. (doi:10. $1111 /$ j.1399-5448.2009.00547.x)

27 Modan-Moses D, Koren I, Mazor-Aronovitch K, Pinhas-Hamiel O \& Landau H. Treatment of congenital hyperinsulinism with lanreotide acetate (Somatuline Autogel). Journal of Clinical Endocrinology and Metabolism 201196 2312-2317. (doi:10. 1210/jc.2011-0605)

28 Bakker B \& Oostdijk W. Diagnosis and management of congenital hyperinsulinism: a case report. European Journal of Endocrinology 2006155 S153-S155. (doi:10.1530/eje.1.02266)

29 Wilson ME \& Tanner JM. Somatostatin analog treatment slows growth and the tempo of reproductive maturation in female rhesus monkeys. Journal of Clinical Endocrinology and Metabolism 199479 495-501. (doi:10.1210/jc.79.2.495)

Received 1 August 2011

Revised version received 25 October 2011

Accepted 31 October 2011 